\title{
Taking maternal services to pregnant women: The community midwifery model
}

The Safe Motherhood Demonstration Project

Follow this and additional works at: https://knowledgecommons.popcouncil.org/departments_sbsr-rh How does access to this work benefit you? Let us know!

\section{Recommended Citation}

"Taking maternal services to pregnant women: The community midwifery model," Safe Motherhood Policy Alert. Nairobi: Population Council, 2005. 


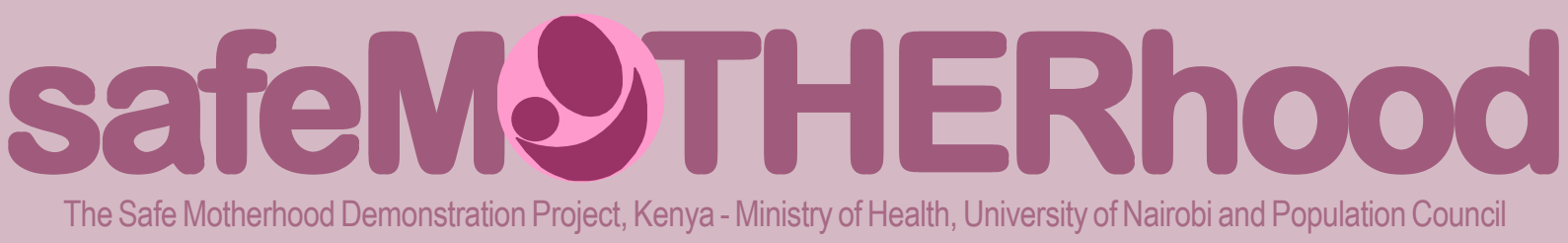

\section{Taking Maternal Services to Pregnant Women:The Community Midwifery Model}

E vidence from a number of studies globally ${ }^{1}$ has shown a reduction in maternal and perinatal mortality when women have a skilled attendant present at every birth. In Kenya, although over $88 \%$ of women attend an antenatal clinic at least once during pregnancy a skilled attendant assists only $42 \%$ at birth. There are regional disparities within Kenya on who provides support during childbirth. In Central Province, over $70 \%$ deliver with a skilled attendant compared to $28 \%$ in Western Province ${ }^{2}$.

Results from one district in Western Province ${ }^{3}$ where midwives were given the necessary equipment and support to assist women during birth at home, showed a significant increase in home births attended by skilled health workers from 1\% to 9\% between 2001 and 2003 and a similar decrease in utilisation of the Traditional Birth Attendants. This is an indication that skilled attendance in the community is possible and a good alternative for women who are unable to reach a health facility for whatever reason.

Building on these results, a Community Midwifery Model was developed by a collaborative group of professionals including; Division of Reproductive Health, $\mathrm{MOH}$, the Kenya Nursing Council, National Nurses Association of Kenya (including the Midwifery Chapter and Private Nurses), Kenya Obstetrical and Gynaecological Society and Population Council.
The Community Midwifery Model focuses on empowering the midwives living in the community to assist women during pregnancy, childbirth and the postpartum period in their homes, manage minor complications and facilitate prompt referral when necessary with a backup referral mechanism to ensure speedy transfer to hospital.

The community midwifery model operates from an understanding that:

- Pregnancy and childbirth is, in the majority of cases, a normal life event that will proceed to an uncomplicated outcome;

- Women make informed choices when a wide range of unbiased information is readily available;

- Midwives are educated and experienced in providing essential obstetric care, life saving skills and diagnosing deviations that require consultation or specialist care; and

- Labour and childbirth can start at any time of the day or night in the absence of any means of communication or transport.

The Community Midwifery Model recruits committed out of work midwives (retired or unemployed) to offer maternal services in the community and provide skilled attendance at birth. The midwives are community based and are not employed by the Ministry of Health. 
However the community and health facility staff (through the facility health committee) work together to develop linkages required for emergency back up referral and support for the midwife. Following a refresher course facilitated by the District $\mathrm{RH}$ Training Team, the midwife will be expected to perform a number of procedures (e.g. focused antenatal care, deliveries, manual removal of retained placenta, early postpartum check), which are recorded in a logbook and signed by the incharge of the maternity.

Once deemed competent the midwife is provided with a delivery kit and consumables for assisting women to give birth at home.The midwife reports her activities (including births attended, sick pregnant women seen and emergency transfers) to the health facility where they may also assist during antenatal/ postnatal clinics. These midwives will update their skills by attending continuing professional development sessions at the facility.

\section{Challenges}

The main challenges to implementing this model include:

- Linkages with the formal health system;

- Communication and transport when referral is needed;

- Source of the initial supplies, drugs and equipment;

- Community involvement, support and linkages with Community Own Resource Persons (including TBAS);

- Service charges for the very poor;

- Policy issues: licensing / certification;

- Sustainability.

\section{Policy Implications}

Policy formulation strengthens programme commitment and sets an enabling environment for programmes, giving them credibility and visibility. For the Community Midwifery Model to gain momentum, the following issues will need to be included in the RH policy:

- The Nursing Council and the MOH to consider and agree on a specific "certificate to work" for Community Midwives which will be issued by the $\mathrm{DMOH}$;
- Clarification that skilled attendance at home is allowed by the Ministry of Health;

- A clear policy directive of how the community midwife will link with the formal health system;

- The role of the community and the health sector in setting up and maintaining referral mechanisms; (emergency transport funds etc)

- Community involvement to ensure the model is sustainable through prepayment schemes and flexible modes of payment for home birth services; and

- Linkages/ networking with other community based care programs to promote information exchange, build alliances and help create complementary and reinforcing programs E.g. PMTCT, IMCI and Home Based Care.

\section{Conclusion}

The community midwifery model was developed to try to meet the needs of women unable to access facility based care during pregnancy, childbirth and after delivery by taking the services to the women in the community and ensuring the back up for emergency referral to hospital. It can ensure personalised comprehensive ANC as well as continuous skilled care during and after childbirth.

Strengthening this model with a functional referral system, competent and skilled health care providers in the health facilities, appropriate health information, community mobilisation and a strong and supportive health management team will contribute to the strategy of phasing out TBAs to increase Skilled Attendants for all women at birth. The anticipated reduction in maternal and perinatal morbidity and mortality will contribute to the achievement of themillennium development goals.

1 WHO 2004, Making pregnancy safer: the critical role of the skilled attendant. A joint statement by WHO, ICM and FIGO

2 Kenya Demographic Health Survey 2003

3 Population Council, MOH, UoN: 2004 SMDP, Western Province: Approaches to providing quality maternal care in Kenya 